\title{
Using Andersen's Behavioural Model of Health Services use to Examine usage of Intermittent Preventive Treatment of Malaria in Pregnancy in Nigeria
}

Bola Lukman Solanke ( $\nabla$ modebolasolanke@gmail.com )

Obafemi Awolowo University

Yinusa Rasheed Adebayo

Federal University

Olaoye James Oyeleye

Obafemi Awolowo University

Omolayo Bukola Oluwatope

Obafemi Awolowo University

Benjamin Bukky llesanmi

Obafemi Awolowo University

Tosin Olajide Oni

Obafemi Awolowo University

\section{Research Article}

Keywords: Malaria in pregnancy, IPTp, Andersen model, women, Nigeria

Posted Date: November 12th, 2021

DOl: https://doi.org/10.21203/rs.3.rs-745099/v1

License: (c) This work is licensed under a Creative Commons Attribution 4.0 International License.

Read Full License 


\section{Abstract}

Background: Studies in Nigeria and elsewhere in sub-Saharan Africa have explored factors influencing usage of intermittent preventive treatment of malaria in pregnancy (IPTp). However, most of the studies are not model or theory-based, which provides less satisfactory guidance to malaria control programming. This study fills the knowledge gap by adapting the Andersen's behavioural model of health services use to IPTp usage in Nigeria.

Methods: This study adopted a cross-sectional design that utilised secondary data extracted from the 2018 Nigeria Demographic and Health Survey (NDHS). A weighted sample of 4,772 women who had deliveries in the past year preceding the survey was analysed. The outcome variable was usage of IPTp dichotomised into optimal or otherwise. The explanatory variables cut across individual and community levels, and were divided into predisposing, enabling and need factors in line with the theoretical constructs of the Andersen model. Two multilevel mixed-effects logistic regression models were fitted to identify the factors influencing optimal usage of IPTp. Analyses were performed using Stata 14. Statistical significance was set at $5 \%$.

Results: The realised level of optimal IPTp usage was $21.8 \%$. The factors that either predispose or enables a pregnant woman to take optimal doses of IPTp are age, education, being employed, being autonomous on own healthcare, health insurance enrolment, partner education, receiving antenatal care in public health facility, rural residence, being resident in northern geo-political zones, community literacy level, and community perception of the consequences of malaria. Two significant need factors affecting optimal usage of IPTp are timing of first antenatal care contact and actual sleeping under mosquito bed net.

Conclusion: Optimal usage of IPTp is low among pregnant women in Nigeria. There is need to devise additional public health education programme promoting IPTp usage through the formation of Advocacy, Communication and Social Mobilisation (ACSM) core group in every ward in all the local government areas in the country. In addition, health planners in the country should adopt the use of the Andersen model for assessing key determinants of IPTp usage among childbearing women in the country.

\section{Background}

Malaria in pregnancy is a specific health condition peculiar only to pregnant women and characterised by the presence of malaria parasite in the red blood cells of the placental. It has serious adverse effects on the health of pregnant women, the foetus, and the neonate [1]. Malaria in pregnancy elevate the risks of maternal mortality or severe morbidity such as maternal anaemia among pregnant women. It may also result in still birth, preterm birth, and low birth weight, all of which increase the risk of infant and child mortality [1]. Based on WHO statistics, out of the estimated 33 million pregnancies in Africa, 12 million of the pregnancies (35\%) were exposed to malaria infection in 2019. Across Africa, the prevalence of malaria in pregnancy is higher in Central and West Africa with Nigeria contributing a substantial 
proportion of women infected with malaria during pregnancy [2]. Apart from the rate of infection among pregnant women in the country, malaria is a key factor responsible for substantial proportions of infant and under-five deaths [3]. Malaria also accounts for nearly 60 percent of hospital outpatient attendance and 30 percent of hospital admissions in Nigeria. This takes heavy toll on the inadequate healthcare delivery system in the country [4]. Malaria in pregnancy is thus a major public health problem requiring effective strategies in Nigeria where malaria remains endemic in all parts of the country [5].

Across developing countries, intermittent preventive treatment of malaria in pregnancy (IPTp) is one of the malaria control interventions widely promoted by the WHO to prevent malaria during pregnancy [6]. However, other malaria control interventions also being implemented in Nigeria include use of LongLasting Insecticidal Nets (LLINs), Indoor Residual Spraying (IRS), and Larval Source Management [7]. Attention on the IPTp emanate from increasing evidence that its use substantially reduces the risks of adverse maternal and fetal outcome $[1,8]$. This is important because adverse maternal and child health outcomes remain crucial public health concerns in many developing countries. Currently in Nigeria, Sulfadoxine-pyrimethamine (SP) under the brand name Fansidar is the government approved medicine for IPTp in Nigeria. Pregnant women are expected to receive the therapy during routine antenatal care visits. The WHO recommends that pregnant women should receive at least three doses of the IPTp before delivery [6].

Evidence however shows that in Nigeria and many other sub-Sahara African countries, the uptake of optimal doses of IPTp (3 or more doses) by pregnant women remains low and below national targets [915]. For example, in the 2018 Nigeria Demographic and Health Survey (NDHS), the prevalence of IPTp optimal doses of SP/Fansidar was $17 \%$ among childbearing women who had deliveries in the two years preceding the survey. There is need for further studies to identify more underlying factors of optimal usage of IPTp. This is important because low coverage reflects missed opportunities not only to deliver IPTp to pregnant women [16] but also missed opportunities to reduce adverse maternal and child health outcomes [17] in the country. Studies in Nigeria [18-20, 12] and elsewhere in sub-Saharan Africa [13-14] have explored the factors influencing use of IPTp with many of the studies identifying some important determinants of IPTp usage across sub-Saharan Africa. The identified determinants among others include type of antenatal care facility, health insurance enrolment, number of antenatal care visits [21], education, parity [22], timing of first antenatal visit [23], employment [24], place of residence [25], geographical region [13], knowledge of malaria preventive strategies [26], maternal age, and household wealth index [27-28].

However, most of the studies are not model or theory-based. This is less satisfactory due to three reasons. Firstly, non-use of models or theories in public health research may not properly guide health planners and policy makers in malaria control programming by not showcasing the interacting causal influences on usage of malaria prevention strategies. Secondly, models and theories are crucial to developing evidence-based health programmes [29] particularly in the promotion of new malaria control interventions. Thirdly, the use of models and theories provide a framework for malaria programme planners to build upon in efforts to develop more workable initiatives. Though, one Nigerian study [30] 
adapted the socio-ecological model to IPTp usage, the study was however qualitative in nature and did not generate quantitative hierarchical data for the validation of the model. This study fills the knowledge gap by adapting the Andersen's behavioural model of health services use to IPTp usage in Nigeria.

The Andersen model is one of the analytical behavioural models developed in the 1960s to enhance identification and measurement of the diverse factors affecting family access to health care [31-32]. In its basic assertions, the model posits that utilisation of health services could be primarily explained by three sets of factors, namely, predisposing (sets of socio-demographic characteristics that may increase or reduce the likelihood of healthcare use prior to the need for a particular health service), enabling (sets of individual, household or health service resources that facilitate access to a particular health service), and need (conditions that show potential need for a particular healthcare service) factors. The model depicts four types of access to health care services. These are potential access which connote the availability of enabling resources or infrastructure; realised access which refer to the actual utilisation of the available health services; equitable access which occur when the three factors sufficiently explained the variation in health services use; and inequitable access which occur when the predisposing and enabling factors as well as health beliefs sufficiently explained health care utilisation [33].

Further modifications to the model have led to the inclusion of more variables to the Andersen model. These include healthcare system and personal health practices-related factors. In its current form, the model prescribes exploring contextual and individual factors affecting health services use [33]. Studies have adapted the Andersen model to the utilisation of diverse healthcare services such as antenatal care [34], institutional delivery [35], adolescent use of reproductive health services [36], HIV testing services [37], contraceptive use [38], and long-term services and support for older adults [39]. Findings in these studies have provided strength for the assertions of the model. The findings have also made contributions to the clarity of concepts and measures relevant to health care policy and programming. Based on the current theoretical position of the Andersen model, this study examines the individual and contextual factors influencing IPTp usage in Nigeria. This was with the view to informing the 2014-2020 National Malaria Strategic Plan (NMSP) currently being implemented in the country [7]. The NMSP targets ensuring that the country achieves her desire of transiting from malaria control to malaria elimination by using community structures to deliver diverse malaria interventions to the populace including pregnant women. The objective of the study was to examine the factors influencing optimal usage of IPTp in Nigeria based on the Andersen analytical framework.

\section{Methods}

\section{Data Source}

The study adopted a cross-sectional research design that utilised secondary data extracted from the 2018 Nigeria Demographic and Health Survey (NDHS). The NDHS was implemented in the country by the National Population Commission (NPC) in collaboration with the National Malaria Elimination Programme (NMEP) [40]. The Demographic and Health Survey (DHS) Programme provided technical 
support for the implementation of the survey. Major international organisations such as Bill and Melinda Gates Foundation, The Global Fund, World Health Organisation (WHO), United States Agency for International Development (USAID), and United Nations Population Fund (UNFPA) provided funding support for the survey. The 2018 NDHS provided reliable information on basic demographic and health characteristics of the Nigerian populace including national information about malaria infection, treatment and control [40]. The data were analysed with authorisation from MEASURE DHS, and its available online via https://dhsprogram.com/data/.

\section{Procedure}

The 2018 NDHS sampled survey participants using a multi-stage sampling technique that ensured a nationally representative sample. The whole country was stratified into urban and rural areas after which some urban and rural areas were selected randomly. The selection was based on localities used as Enumeration Areas (EAs) in the penultimate national housing and population census. The EAs served as the primary sampling unit (cluster) in the survey. In the selected EAs, households were randomly selected for the survey following appropriate household listing. From the selected households, eligible men aged 15-59 and women aged 15-49 were randomly selected for the survey. Comprehensive details of the methodology adopted for the 2018 NDHS have been widely published [40].

\section{Participants}

Though, the 2018 NDHS covered 41,821 women of reproductive age. Women who had no live birth in the past year preceding the survey (34,549 women), women who had less than three antenatal care visits (2,359 women), and women who do not know their number of antenatal care visits ( 178 women) were excluded from the analysis. The inclusion criteria were having had at least a live birth in the past year preceding the survey, and having had at least three antenatal care visits during the last pregnancy. These criteria resulted in a weighted sample size of 4,772 women.

\section{Measures}

The outcome variable in the study was usage of IPTp through the use of Sulfadoxine-pyrimethamine (SP) under the brand name Fansidar. This was measured in the study by the number of IPTp dose a woman received during her last pregnancy. We categorised the responses into two, namely optimal (woman receives 3 or more doses) or otherwise (woman receives less than 3 doses). This categorisation was not only based on the WHO recommendation that pregnant women should take at least 3 doses of IPTp before delivery [6]. It was also consistent with categories adopted in many existing studies [23, 22, $14,13]$. The explanatory variables examined in the study cut across individual and community levels, and were selected based on existing literature [21-22, 13-14, 18-19]. The variables were however divided into predisposing, enabling and need factors in line with the theoretical constructs of the Andersen model. 
The predisposing factors are age group (15-24, 25-34, and 35+), parity (primiparity, multiparity, and grand multiparity), formal education (none, primary, secondary, and higher), employment status (unemployed or employed), autonomy on own health care (not autonomous or autonomous), household wealth (poorest, poorer, middle, richer, and richest), place of residence (urban or rural), geo-political zone (north-central, north-east, north-west, south-east, south-south, and south-west), proportion in community who perceived that malaria can cause death (low, middle, and high), and proportion in community who perceived that malaria is easy to treat (low, middle, and high).

The enabling factors are health insurance enrolment (not enrolled or enrolled), source of antenatal care (government or private), partner education (none, primary, secondary, and higher), community literacy level (low, middle, and high). The need factors are experience of death of a child (ever or never experienced), timing of first antenatal visit (first trimester, second trimester, and third trimester), possession of mosquito bed net for sleeping (no or yes), and actual sleeping under mosquito bed net (no or yes). A number of these variables were re-coded in the study. The community variables were generated from individual responses through aggregation at the cluster level, and then divided into three equal proportions (low, middle and high), using tertile value as cut off reference. This method is generally used for the generation of community variables using DHS data sets [41-45].

\section{Data analysis}

Two types of analyses were carried out. Firstly, frequency distribution was used to describe the sociodemographic characteristics of the respondents as well as the realised access to IPTp. Secondly, two multilevel mixed-effects logistic regression models were fitted to examine the predictors of optimal usage of IPTp. Prior to fitting the model, three mini analyses were carried out. One, variables were selected into the two models based on results of a bivariate analysis. Any variable not showing significance at $p<0.025$ was not selected. Two, a Variance Inflation Factor (VIF) was performed to ensure no multicollinear variable was selected for modelling. The bench mark for this test was that no variable with VIF score of five or higher values should be selected into the models [46]. Three, a 'null model' was fitted. This model did not include any explanatory variables. The essence of the null model was to ascertain whether significant variation exists in the optimal usage of IPTp across the communities. This is determined by the significance of the intercept of the model. Model 1 used the predisposing and enabling factors to explain inequitable use of IPTp in the country. Model 2 used all the predictor variables to examine equitable use of IPTp in Nigeria. The analytical tool adopted not only aligned with the theoretical position of the Andersen model but is also suitable for examining predictors of an outcome with hierarchical influences such as individual and community levels. This tool is widely applied in multilevel studies [4145]. The multilevel mixed-effects logistic model partitions influences on an outcome into fixed and random effects [47]. The fixed effects in the current study were examined using the adjusted Odds Ratio (aOR) while the random effects were examined using the Intra-Cluster Correlation Coefficient (ICC). The ICC which ranges from zero to one indicate the importance of the community factors in the overall variance observed in the outcome variable. The models were check for adequacy using the Akaike 
Information Criterion (AIC). The model with the lowest AIC value is dim to have the best goodness-of-fit. All analyses were performed using Stata 14 [48]. Statistical significance was set at $5 \%$.

\section{Results}

\section{Respondents' socio-demographic profile and IPTp usage}

Table 1 presents the socio-demographic profile of respondents. Women in the age group 25-34 years were more than half of the sample (51.6\%). Nearly half of the women (48.3\%) were multiparous (had between two to four children). However, nearly one-third (31.1\%) of respondents were grand multiparous (had five or more children). Nearly one-third of the women (32.9\%) had no formal education, while slightly more than two-fifths of respondents (40.2\%) attained secondary level of education. With the exception of women in the poorest households, the distribution of household wealth level was similar among respondents. Two-thirds of respondents (66.5\%) were employed. However, more than half of them (57.1\%) had no autonomy on their own healthcare. Nearly all the respondents did not enrol for the national health insurance scheme. 
Table 1

Respondents' socio-demographic characteristics and realised usage of IPTp

Characteristic
Frequency Percentage Characteristic

$(n=$
$4,772)$
Frequency Percentage

$(n=$
$4,772)$

\begin{tabular}{|c|c|c|c|c|c|}
\hline IPTp dose & & & Death of a child & & \\
\hline Otherwise & 3,731 & 78.2 & Ever experienced & 1,306 & 27.4 \\
\hline Optimal & 1,041 & 21.8 & $\begin{array}{l}\text { Never } \\
\text { experienced }\end{array}$ & 3,466 & 72.6 \\
\hline Maternal age group & & & Timing of first ante & latal care & \\
\hline $15-24$ & 1,472 & 30.8 & First trimester & 1,198 & 25.1 \\
\hline $25-34$ & 2,461 & 51.6 & Second trimester & 3,512 & 73.6 \\
\hline $35+$ & 839 & 17.6 & Third trimester & 62 & 1.3 \\
\hline Parity & & & Possession of mos & quito bed & \\
\hline Primiparity (one child) & 984 & 20.6 & No & 1,323 & 27.7 \\
\hline $\begin{array}{l}\text { Multiparity (2-4 } \\
\text { children) }\end{array}$ & 2,306 & 48.3 & Yes & 3,449 & 72.3 \\
\hline $\begin{array}{l}\text { Grand multiparity (5+ } \\
\text { children) }\end{array}$ & 1,482 & 31.1 & Actual sleeping un & er bed ne & \\
\hline Maternal education & & & No & 1,970 & 41.3 \\
\hline None & 1,569 & 32.9 & Yes & 2,802 & 58.7 \\
\hline Primary & 740 & 15.5 & Place of residence & & \\
\hline Secondary & 1,917 & 40.2 & Urban & 2,216 & 46.4 \\
\hline Higher & 546 & 11.4 & Rural & 2,556 & 53.6 \\
\hline Household wealth & & & Geo-political zone & & \\
\hline Poorest & 654 & 13.7 & North-central & 642 & 13.5 \\
\hline Poorer & 923 & 19.3 & North-east & 822 & 17.2 \\
\hline Middle & 1,044 & 21.9 & North-west & 1,539 & 32.2 \\
\hline Richer & 1,092 & 22.9 & South-east & 628 & 13.2 \\
\hline Richest & 1,059 & 22.2 & South-south & 415 & 8.7 \\
\hline Work status & & & South-west & 726 & 15.2 \\
\hline Unemployed & 1,597 & 33.5 & Community literac & level & \\
\hline
\end{tabular}




\begin{tabular}{|c|c|c|c|c|c|}
\hline Characteristic & $\begin{array}{l}\text { Frequency } \\
(n= \\
4,772)\end{array}$ & Percentage & Characteristic & $\begin{array}{l}\text { Frequency } \\
(n= \\
4,772)\end{array}$ & Percentage \\
\hline Employed & 3,175 & 66.5 & Low & 1,569 & 32.9 \\
\hline \multicolumn{3}{|c|}{ Autonomy on own healthcare } & Middle & 1,551 & 32.5 \\
\hline Not autonomous & 2,724 & 57.1 & High & 1,652 & 34.6 \\
\hline Autonomous & 2,048 & 42.9 & \multicolumn{3}{|c|}{$\begin{array}{l}\text { Proportion in community who perceived } \\
\text { malaria is easy to treat }\end{array}$} \\
\hline \multicolumn{3}{|c|}{ Health insurance enrolment } & Low & 1,576 & 33.0 \\
\hline Not enrolled & 4,654 & 97.5 & Middle & 1,888 & 39.6 \\
\hline Enrolled & 118 & 2.5 & High & 1,308 & 27.4 \\
\hline \multicolumn{3}{|l|}{ Partner education } & \multicolumn{3}{|c|}{$\begin{array}{l}\text { Proportion in community who perceived } \\
\text { malaria can cause death }\end{array}$} \\
\hline None & 1,380 & 28.9 & Low & 1,462 & 30.6 \\
\hline Primary & 587 & 12.3 & Middle & 1,702 & 35.7 \\
\hline Secondary & 1,834 & 38.4 & High & 1,608 & 33.7 \\
\hline Higher & 971 & 20.4 & & & \\
\hline \multicolumn{6}{|c|}{ Source of antenatal care } \\
\hline Public health facility & 3,842 & 80.5 & & & \\
\hline Private health facility & 930 & 19.5 & & & \\
\hline
\end{tabular}

The distribution of respondents by partner education was similar to that of maternal education, but the proportion of women with no formal education was higher than that of their partners (32.9\% vs. $28.9 \%)$. The majority of respondents $(80.5 \%)$ received antenatal care from public health facility. The majority $(72.6 \%)$ had never experienced death of a child. The second trimester of pregnancy was the dominant period when majority of the women $(73.6 \%)$ had their first antenatal care visit. While the majority of respondents $(72.3 \%)$ had mosquito bed net, only $58.7 \%$ of the women actually slept under mosquito bed net. More than half of the respondents $(53.6 \%)$ were rural dwellers. Women from the northern geo-political zones were dominant in the sample. The distribution of the level of community literacy was nearly equal among the respondents. More women reside in communities with moderate proportions who perceived either that malaria is easy to treat or that malaria could cause death. The realised level of optimal IPTp usage among the women was $21.8 \%$ compared with the majority $(78.2 \%)$ who received less than the optimal doses of IPTp during pregnancy.

\section{Factors influencing optimal usage of IPTp}


Table 2 presents the fitted multilevel mixed-effects logistic regression models. Model checking reveal that the models were adequate with Model 2 showing a better fit $(\mathrm{AIC}=0.046)$ than Model $1(\mathrm{AIC}=0.721)$. The null model (not shown) reveals that the variance in IPTp usage across the communities was high (ICC = 0.731). But the ICC values decline consistently in successive models as more variables are included in the models. Nevertheless, the ICC in Models 1 and 2 confirm the significance of the contextual factors. When the predisposing and enabling factors were included in Model 1, all the included variables with the exclusion of parity showed significant influence on optimal usage of IPTp. The likelihood of optimal IPTp usage was higher among women in age group $35+$ compared to younger women $(\mathrm{aOR}=2.118,95 \% \mathrm{Cl}$ : 1.259-3.564). As maternal education improved from secondary to higher, the odds of optimal IPTp usage also increased consistently. Likewise, as household wealth improved from richer to richest, the odds of optimal IPTp usage increased. Employed women were more than three times more likely to utilise optimal doses of IPTp compared to unemployed women ( $\mathrm{aOR}=3.292,95 \% \mathrm{Cl}$ : 2.670-4.059). Women who were autonomous on own healthcare and women who enrolled in health insurance scheme had higher likelihood of optimal IPTp usage. 
Table 2

Fixed and random effects on optimal IPTp usage in Nigeria

\section{Characteristics predicting IPTp optimal use}

Model 1

aOR
Model 2

aOR

$\mathrm{p}-$
value p-
value

$95 \% \mathrm{Cl}$

\section{Maternal age group}

\begin{tabular}{llllllll}
$15-24 \mathrm{RC}$ & 1.000 & - & - & 1.000 & - & - \\
\hline $25-34$ & $1.491^{*}$ & 0.027 & $\begin{array}{l}1.047- \\
2.124\end{array}$ & 1.243 & 0.210 & $\begin{array}{l}0.885- \\
1.746\end{array}$ \\
$35+$ & & & & & & \\
& $2.118^{*}$ & 0.005 & $1.259-$ & $1.643^{*}$ & 0.049 & $1.002-$ \\
& & & 3.564 & & & 2.694
\end{tabular}

\section{Parity}

Primiparity ${ }^{R C}$

1.000

1.000

Multiparity

1.165

0.407

$0.812-$

1.670

1.338

0.115

$0.932-$

1.923

Grand multiparity

0.903

0.677

$0.560-$

1.221

0.425

$0.747-$

1.458

1.994

\section{Maternal education}

\begin{tabular}{|c|c|c|c|c|c|c|}
\hline None ${ }^{R C}$ & 1.000 & - & - & 1.000 & - & - \\
\hline Primary & 1.270 & 0.276 & $\begin{array}{l}0.826- \\
1.951\end{array}$ & 0.915 & 0.680 & $\begin{array}{l}0.599- \\
1.397\end{array}$ \\
\hline Secondary & $2.203^{\star \star}$ & $\begin{array}{l}\mathrm{p}< \\
0.01\end{array}$ & $\begin{array}{l}1.045- \\
2.363\end{array}$ & 1.543 & 0.053 & $\begin{array}{l}0.994- \\
2.396\end{array}$ \\
\hline Higher & $2.488^{\star \star}$ & $\begin{array}{l}\mathrm{p}< \\
0.01\end{array}$ & $\begin{array}{l}1.536- \\
4.0311\end{array}$ & $4.073^{\star *}$ & $\begin{array}{l}\mathrm{p}< \\
0.01\end{array}$ & $\begin{array}{l}3.467- \\
4.786\end{array}$ \\
\hline
\end{tabular}

\section{Household wealth}

\begin{tabular}{|c|c|c|c|c|c|c|}
\hline Poorest ${ }^{R C}$ & 1.000 & - & - & 1.000 & - & - \\
\hline Poorer & 1.565 & 0.312 & $\begin{array}{l}0.657- \\
3.727\end{array}$ & 0.855 & 0.524 & $\begin{array}{l}0.529- \\
1.384\end{array}$ \\
\hline Middle & 1.969 & 0.142 & $\begin{array}{l}0.798- \\
4.859\end{array}$ & 0.834 & 0.485 & $\begin{array}{l}0.501- \\
1.388\end{array}$ \\
\hline Richer & $3.717 *$ & $\begin{array}{l}\mathrm{p}< \\
0.01\end{array}$ & $\begin{array}{l}2.855- \\
4.838\end{array}$ & 0.745 & 0.310 & $\begin{array}{l}0.422- \\
1.314\end{array}$ \\
\hline
\end{tabular}

Notes: RC (Reference category), ${ }^{*} p<0.05,{ }^{* \star} p<0.01$ 


\begin{tabular}{|c|c|c|c|c|c|c|}
\hline \multirow{2}{*}{$\begin{array}{l}\text { Characteristics predicting IPTp } \\
\text { optimal use }\end{array}$} & \multicolumn{3}{|l|}{ Model 1} & \multicolumn{3}{|l|}{ Model 2} \\
\hline & aOR & $\begin{array}{l}\mathrm{p}- \\
\text { value }\end{array}$ & $95 \% \mathrm{Cl}$ & aOR & $\begin{array}{l}\text { p- } \\
\text { value }\end{array}$ & $95 \% \mathrm{Cl}$ \\
\hline Richest & $4.158^{\star \star}$ & $\begin{array}{l}p< \\
0.01\end{array}$ & $\begin{array}{l}3.171- \\
5.452\end{array}$ & 1.200 & 0.578 & $\begin{array}{l}0.632- \\
2.279\end{array}$ \\
\hline \multicolumn{7}{|l|}{ Work status } \\
\hline Unemployed RC & 1.000 & - & - & 1.000 & - & - \\
\hline Employed & $3.292^{\star \star}$ & $\begin{array}{l}\mathrm{p}< \\
0.01\end{array}$ & $\begin{array}{l}2.670- \\
4.059\end{array}$ & $2.591^{\star \star}$ & $\begin{array}{l}\mathrm{p}< \\
0.01\end{array}$ & $\begin{array}{l}2.227- \\
3.014\end{array}$ \\
\hline \multicolumn{7}{|l|}{ Autonomy on own healthcare } \\
\hline Not autonomous $\mathrm{RC}$ & 1.000 & - & - & 1.000 & - & - \\
\hline Autonomous & $2.058^{\star}$ & 0.005 & $\begin{array}{l}1.247- \\
3.397\end{array}$ & $2.015^{\star}$ & 0.042 & $\begin{array}{l}1.026- \\
3.957\end{array}$ \\
\hline \multicolumn{7}{|l|}{ Health insurance enrolment } \\
\hline Not enrolled RC & 1.000 & - & - & 1.000 & - & - \\
\hline Enrolled & $1.765^{\star \star}$ & $\begin{array}{l}\mathrm{p}< \\
0.01\end{array}$ & $\begin{array}{l}1.418- \\
2.197\end{array}$ & $1.259 *$ & 0.040 & $\begin{array}{l}1.011- \\
1.568\end{array}$ \\
\hline \multicolumn{7}{|l|}{ Partner education } \\
\hline None RC & 1.000 & - & - & 1.000 & - & - \\
\hline Primary & $4.647^{\star \star}$ & $\begin{array}{l}p< \\
0.01\end{array}$ & $\begin{array}{l}2.641- \\
8.176\end{array}$ & $3.882^{\star \star}$ & $\begin{array}{l}p< \\
0.01\end{array}$ & $\begin{array}{l}2.273- \\
6.631\end{array}$ \\
\hline Secondary & $5.058 * \star$ & $\begin{array}{l}p< \\
0.01\end{array}$ & $\begin{array}{l}2.949- \\
8.676\end{array}$ & $4.798 * \star$ & $\begin{array}{l}\mathrm{p}< \\
0.01\end{array}$ & $\begin{array}{l}2.836- \\
8.119\end{array}$ \\
\hline Higher & $2.997 * \star$ & $\begin{array}{l}p< \\
0.01\end{array}$ & $\begin{array}{l}1.733^{-} \\
5.185\end{array}$ & $3.786 * \star$ & $\begin{array}{l}p< \\
0.01\end{array}$ & $\begin{array}{l}2.142- \\
6.690\end{array}$ \\
\hline \multicolumn{7}{|l|}{ Source of antenatal care } \\
\hline Public health facility $\mathrm{RC}$ & 1.000 & - & - & 1.000 & - & - \\
\hline Private health facility & $1.909 * *$ & $\begin{array}{l}\mathrm{p}< \\
0.01\end{array}$ & $\begin{array}{l}1.292- \\
2.820\end{array}$ & $2.263^{\star}$ & 0.024 & $\begin{array}{l}1.116- \\
4.591\end{array}$ \\
\hline \multicolumn{7}{|l|}{ Place of residence } \\
\hline Urban RC & 1.000 & - & - & 1.000 & - & - \\
\hline
\end{tabular}

Notes: RC (Reference category), ${ }^{*} \mathrm{p}<0.05,{ }^{*} \mathrm{p} p 0.01$ 


\begin{tabular}{|c|c|c|c|c|c|c|}
\hline \multirow{2}{*}{$\begin{array}{l}\text { Characteristics predicting IPTp } \\
\text { optimal use }\end{array}$} & \multicolumn{3}{|l|}{ Model 1} & \multicolumn{3}{|l|}{ Model 2} \\
\hline & aOR & $\begin{array}{l}\text { p- } \\
\text { value }\end{array}$ & $95 \% \mathrm{Cl}$ & aOR & $\begin{array}{l}\mathrm{p}- \\
\text { value }\end{array}$ & $95 \% \mathrm{Cl}$ \\
\hline Rural & $0.566^{\star}$ & 0.038 & $\begin{array}{l}0.331- \\
0.968\end{array}$ & $0.425^{\star \star}$ & $\begin{array}{l}\mathrm{p}< \\
0.01\end{array}$ & $\begin{array}{l}0.239- \\
0.753\end{array}$ \\
\hline \multicolumn{7}{|l|}{ Geo-political zone } \\
\hline North-central RC & 1.000 & - & - & 1.000 & - & - \\
\hline North-east & 1.006 & 0.956 & $\begin{array}{l}0.807- \\
1.255\end{array}$ & 1.031 & 0.915 & $\begin{array}{l}0.592- \\
1.794\end{array}$ \\
\hline North-west & $0.745^{\star}$ & 0.013 & $\begin{array}{l}0.591- \\
0.939\end{array}$ & $0.447^{*}$ & 0.009 & $\begin{array}{l}0.244- \\
0.819\end{array}$ \\
\hline South-east & $3.717^{\star *}$ & $\begin{array}{l}p< \\
0.01\end{array}$ & $\begin{array}{l}2.855- \\
4.838\end{array}$ & $5.045^{\star \star}$ & $\begin{array}{l}\mathrm{p}< \\
0.01\end{array}$ & $\begin{array}{l}4.057- \\
6.273\end{array}$ \\
\hline South-south & $1.808^{\star \star}$ & $\begin{array}{l}\mathrm{p}< \\
0.01\end{array}$ & $\begin{array}{l}1.382- \\
2.369\end{array}$ & $3.386^{\star}$ & 0.001 & $\begin{array}{l}1.664- \\
6.891\end{array}$ \\
\hline South-west & $2.008^{\star \star}$ & $\begin{array}{l}\mathrm{p}< \\
0.01\end{array}$ & $\begin{array}{l}1.570- \\
2.570\end{array}$ & $4.374^{\star \star}$ & $\begin{array}{l}\mathrm{p}< \\
0.01\end{array}$ & $\begin{array}{l}2.153- \\
8.889\end{array}$ \\
\hline \multicolumn{7}{|l|}{ Community literacy level } \\
\hline Low $\mathrm{RC}$ & 1.000 & - & - & 1.000 & - & - \\
\hline Middle & 0.918 & 0.838 & $\begin{array}{l}0.818- \\
1.177\end{array}$ & 1.042 & 0.858 & $\begin{array}{l}0.664- \\
1.635\end{array}$ \\
\hline High & $1.289 *$ & 0.018 & $\begin{array}{l}1.045- \\
1.589\end{array}$ & $1.749 *$ & 0.030 & $\begin{array}{l}1.055- \\
2.898\end{array}$ \\
\hline \multicolumn{7}{|c|}{ Proportion in community who perceived malaria is easy to treat } \\
\hline Low ${ }^{R C}$ & 1.000 & - & - & 1.000 & - & - \\
\hline Middle & 1.066 & 0.436 & $\begin{array}{l}0.908- \\
1.252\end{array}$ & 1.203 & 0.375 & $\begin{array}{l}0.799- \\
1.812\end{array}$ \\
\hline High & $0.598^{\star \star}$ & $\begin{array}{l}\mathrm{p}< \\
0.01\end{array}$ & $\begin{array}{l}0.491- \\
0.729\end{array}$ & $0.344^{\star *}$ & $\begin{array}{l}\mathrm{p}< \\
0.01\end{array}$ & $\begin{array}{l}0.198- \\
0.597\end{array}$ \\
\hline \multicolumn{7}{|c|}{ Proportion in community who perceived malaria can cause death } \\
\hline Low ${ }^{R C}$ & 1.000 & - & - & 1.000 & - & - \\
\hline Middle & 1.235 & 0.069 & $\begin{array}{l}0.983- \\
1.552\end{array}$ & 1.108 & 0.636 & $\begin{array}{l}0.724- \\
1.698\end{array}$ \\
\hline
\end{tabular}

Notes: RC (Reference category), ${ }^{*} \mathrm{p}<0.05,{ }^{*} \mathrm{p} p 0.01$ 


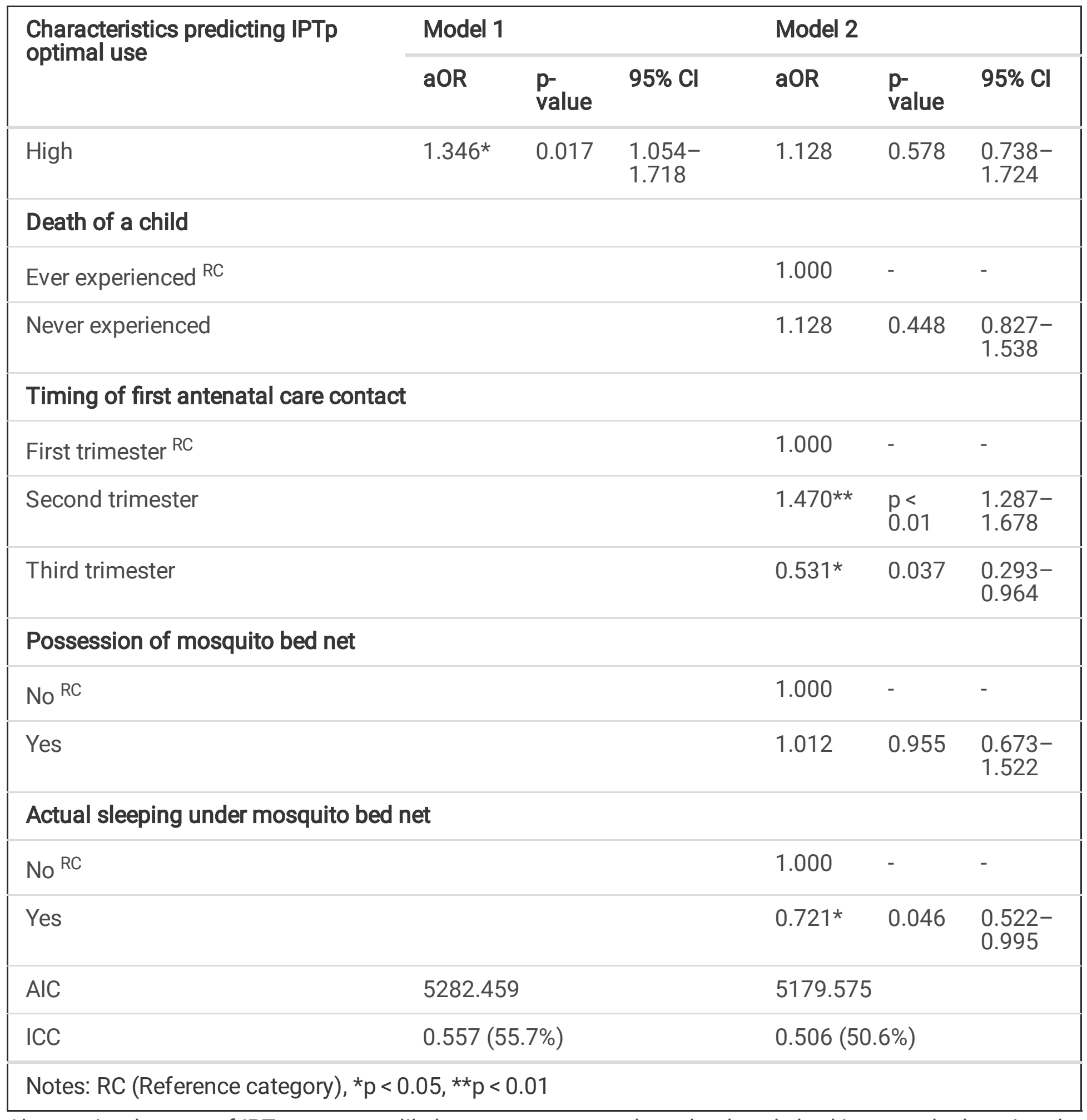

Also, optimal usage of IPTp was more likely among women whose husbands had improved educational attainments excluding higher education. Women who received antenatal care from private health facility were nearly twice more likely to take optimal doses of IPTp compared to women who received antenatal care from public health facility ( $\mathrm{aOR}=1.909,95 \% \mathrm{Cl}: 1.292-2.820)$. Rural women were less likely to take optimal doses of IPTp (aOR $=0.566,95 \% \mathrm{Cl}: 0.331-0.968)$, while women in the three Southern geopolitical zones had higher odds of optimal IPTp doses. Women who resided in communities with high literacy level were $28.9 \%$ more likely to take optimal doses of IPTp compared to those in communities with low literacy level $(\mathrm{aOR}=1.289,95 \% \mathrm{Cl}$ : $1.045-1.589)$. Women who resided in communities with high 
proportion of people who believed malaria is easy to treat had lower odds of IPTp optimal usage ( $\mathrm{aOR}=$ $0.598,95 \% \mathrm{Cl}$ : 0.491-0.729). In contrast, women who resided in communities with high proportion of people who believed that malaria can cause death were more likely to take optimal doses of IPTp compared to other women $(\mathrm{aOR}=1.346,95 \% \mathrm{Cl}: 1.054-1.718)$.

When the need factors are included in Model 2, parity remained an insignificant influence on optimal IPTp usage, while household wealth and proportion of women in community who believed malaria can cause death no longer exert significant influence on the likelihood of taking optimal doses of IPTp. Older women were more likely to take optimal doses of IPTp compared to younger women (aOR $=1.643,95 \% \mathrm{Cl}$ : $1.002-$ 2.694). The influence of maternal education on IPTp usage was weakened in Model 2 compared to Model 1 because in Model 2, only higher education showed significant influence on IPTp optimal usage (aOR = 4.073, 95\% Cl: 3.467-4.786). Employed women, health insurance enrolment and being autonomous on own healthcare were significant predictors of IPTp optimal usage among the women. As partner education improved, the odds of IPTp optimal usage increased consistently until attainment of higher education when a dip occurred. Source of antennal care remain a significant predictor with higher odds among women who received antenatal care from private health facility $(\mathrm{aOR}=2.263,95 \% \mathrm{Cl}: 1.116-$ 4.591). Rural women were less likely to take optimal doses of IPTp compared to urban women ( $\mathrm{aOR}=$ $0.425,95 \% \mathrm{Cl}: 0.239-0.753)$. While women resident in the North-west zone were less likely to optimally utilise IPTp, women resident in all the three southern zones had higher likelihood of optimal IPTp utilisation. Both community literacy level and perception of malaria as easy to treat reveal significant influence on IPTp usage. Two of the need factors reveals significant influence on IPTp optimal usage. Women who had their first antenatal contact in the second trimester of pregnancy were more likely to take the optimal doses $(\mathrm{aOR}=1.470,95 \% \mathrm{Cl}$ : $1.287-1.678)$. Likewise, women who actually slept under mosquito bed net were less likely to take optimal doses of IPTp (aOR $=0.721,95 \% \mathrm{Cl}: 0.522-0.995)$.

\section{Discussion}

This study examined factors influencing optimal usage of IPTp in Nigeria using the framework provided by the Andersen behavioural model of health services use. Using analytical framework such as the Andersen model is important in malaria in pregnancy research because it properly guide health planners and malaria control programmers by improving understanding of the wide spectrum factors underlying IPTp uptake in the country. In addition, developing additional evidence-based malaria elimination programmes in Nigeria may be tailored to the Andersen model. This is because the model reveals sets of predisposing, enabling and need factors at both individual and contextual levels that should be targeted in developing workable malaria elimination strategies.

The study found that the realised usage of optimal doses of IPTp among women with recent deliveries in Nigeria is low (21.8\%). This is consistent with evidence provided in government reports [7] and several hospital or population-based studies $[25,9,11,20,13]$. However, the observed prevalence deviates widely from findings in few other studies $[18,23,22,19,14]$. Two reasons may account for the disparity. Firstly, there is lack of uniformity in the categorisation of IPTp usage in literature. Contrary to the categorisation 
of IPTp usage in this study, many existing studies $[26,11]$ grouped IPTp usage into three or more categories which undermines the opportunity to observe the extent of optimal usage in the studied population. Secondly, many of the studies [28] derive IPTp prevalence among women who had births in the last two or three years, while the current study focused only women who had births in the past one year. The differentials in the group of women examined may be the reason for the different levels of usage observed in this study compared to some existing studies.

Nevertheless, one key take away from the low level of optimal IPTp usage found in this study is that the National Malaria Strategic Plan [7] being implemented in the country needs to be rejuvenated to achieve set objectives. For instance, objective one of the Plan seeks to ensure that at least $80 \%$ of targeted population utilises appropriate preventive measures by 2020 . Since we studied only women who had at least three antenatal contacts, our finding suggests that some of the women may have some barriers in accessing the IPTp which is one of the important preventive measures for pregnant women. This may not only elevate the extent of missed opportunity [17] to reduce adverse maternal and child health outcomes, but also suggests missed opportunities to deliver IPTp to pregnant women [16] in the country. Furthermore, the low level of optimal IPTp usage observed in the study undermines the third objective of the Plan. The Plan seeks to treat all individuals with confirmed malaria detected in public or private facilities with effective antimalaria drug by 2020. Our finding thus suggests that not all confirm cases of malaria among pregnant women are receiving effective care particularly IPTp therapy. The reasons for low usage may probably be due to either poor knowledge of the IPTp by pregnant women [12] or the existence of some health system barriers such as stock out of IPTp and poor training of providers $[25,17$, $10,24,15]$ which adversely affects utilisation. The Federal Ministry of Health may need to devise additional public health education programme that promote IPTp usage by pregnant women. One means of achieving such is by ensuring that in each Local Government Area, the Advocacy, Communication and Social Mobilisation (ACSM) core group suggested in the Plan are constituted in every Ward to further engage the community, and also to distribute more Information, Education and Communication (IEC) materials. The health sector barriers may also be identified and addressed through timely monitoring and evaluation activities.

The study found that the utilisation of optimal usage of IPTp by pregnant women is strongly influenced by their socio-demographic and health-related conditions which either predispose them to poor use or enable optimal usage among them. In line with existing studies $[25,28,22]$ poor maternal education, rural residence and lack of autonomy on own health care hinders optimal usage of IPTp while improvement in such condition facilitate optimal usage of IPTp. Improved education and female autonomy are significant source of empowerment that help women not only to understand health needs but also to access needed health services. Urban residence often promotes use of health services due to more availability of such services in urban settings. It was revealed also that younger age, unemployment and northern residence reduces likely usage of optimal IPTp. These findings are consistent with findings in similar studies [27, $24,13]$. Younger women may have lower usage probably due to insufficient use of healthcare services while unemployed women may face peculiar difficulties such as sourcing money for transportation to 
facility. One likely cause of lower usage in Northern Nigeria is the dominance of Islamic practices which in many instances may not encourage use if female health providers are not available at facilities.

It was revealed in the study that source of antenatal care, health insurance enrolment and partner education significantly enabled optimal usage of IPTp. This agrees with findings in some existing studies $[19,21,13]$. However, contrary to the finding in a recent study in Tanzania [13], we found higher use of IPTp among pregnant women receiving antenatal care in private health facility compared to public health facility. In Nigeria, maternal and child health services are mostly provided in government health facilities. The few pregnant women patronising private facilities are often well-educated and wealthier which may suggest that the facilities patronised are likely to possess sufficient drugs and resources needed for effective treatment. In contrast, the high patronage of public facilities sometimes leads to stock out of drugs which may reduce use. Our study further revealed that timing of first antenatal contact and use of insecticidal treated nets are important conditions that provoke optimal usage of IPTp. This is in consonance with many existing studies $[27,18,23,14,14]$. Early antenatal contact by pregnant women is crucial for prompt detection and effective treatment of malaria. In addition, the IPTp is meant to be given at specified weeks of gestation [6] which presuppose that most pregnant women adhere to the prescribed antenatal care attendance.

In understanding the inferences drawn from the study, it is important to borne in mind that the analyses performed in the study have few drawbacks. One, the data analysed are self-reported data which were not subjected to additional scrutiny. We assumed that the NDHS datasets are trustworthy having been collected through standard procedure. Two, the study only focused the use of the IPTp by pregnant women, whereas there are other types of treatment available to pregnant women which may lead to nonuse of the IPTp. The implication of this fact is that the usage of the IPTp may not accurately mirror malaria control strategies among pregnant women in the country. Three, the data analysed are crosssectional in nature and do not permit any claim of cause-effect. Hence, the use of the term 'influence' in the multivariable analysis actually established strong association between the research variables, and not necessarily causality.

\section{Conclusion}

This study using secondary data analysis examined the factors influencing optimal usage of IPTp in Nigeria. The study was underpinned by the Andersen behavioural model of health services use. The study provided evidence for continued application of the Andersen model in public health research. A number of predisposing, enabling and need factors underlying IPTp optimal usage were identified. Findings implies that the low usage of optimal IPTp may be improved through additional public health education initiative that promotes the IPTp therapy.

\section{Abbreviations}

ACSM Advocacy, Communication and Social Mobilisation

Page $17 / 23$ 
FMoH Federal Ministry of Health

IPTp Intermittent preventive treatment of malaria in pregnancy

IRS Indoor Residual Spraying

LLINs Long Lasting Insecticidal Treated Nets

NDHS Nigeria Demographic and Health Survey

NPC National Population Commission

WHO World Health Organization

NMSP National Malaria Strategic Plan

\section{Declarations}

\section{Ethics approval and consent to participate}

I confirm that all methods were performed in accordance with the relevant guidelines.

The 2018 NDHS survey protocol was review and approved by the ICF Institutional Review Board with approved number ICF IRB FWA00000845. The protocol was also approved in Nigeria by the National Health Research Ethics Committee of Nigeria (NHREC) with NHREC Approval Number

NHREC/01/01/2007. Prior to the interview participants provided both written and verbal consent. Formal request to use the data for the purpose of the study was made by the authors and authorisation was granted by MEASURE DHS, the custodian of the datasets. The analyses are in anonymised forms. The datasets are available in the public domain via https://dhsprogram.com/data/

\section{Consent to publish}

Not Applicable

\section{Availability of data and materials}

Secondary data analysed could be accessed online at https://dhsprogram.com/data/.

\section{Competing Interests}

The authors declare no competing interests. 


\section{Compliance with Guidelines}

I confirm that all methods were performed in accordance with the relevant guidelines

\section{Funding}

Not Applicable

\section{Authors' contributions}

BLS developed the concept with assistance of OBO. YRA and OJO reviewed literature. BLS analysed the data with assistance of $\mathrm{OBO}, \mathrm{BBI}$ and TOO. All authors discussed the results, certified the content, and approved the final manuscript.

\section{Acknowledgements}

The authors express gratitude to MEASURE DHS and National Population Commission (Nigeria) for granting permission to access 2018 NDHS datasets.

\section{Authors' Information}

BLS is Associate Professor in the Department of Demography and Social Statistics, Obafemi Awolowo University, Ile-Ife, Nigeria, while YRA, OJO, OBO, BBI and TOO are graduate students in the Department.

\section{References}

1. Umemmuo MU, Agbogboroma CO, Iregbu KC. The efficacy of intermittent preventive therapy in the eradication of peripheral and placental parasitemia in a malaria-endemic environment, as seen in a tertiary hospital in Abuja, Nigeria. Int J Gynecol Obstet. 2020; 148: 338-343, doi: 10.1002/ijgo.13085

2. World Health Organization. World malaria report 2020: 20 years of global progress and challenges. Geneva: World Health Organization; 2020. Retrieved from https://www.who.int/publications/i/item/9789240015791

3. Morakinyo OM, Balogun FM, Fagbamigbe AF. Housing type and risk of malaria among under- five children in Nigeria: evidence from the malaria indicator survey. Malar J. 2018; 17:311, https://doi.org/10.1186/s12936-018-2463-6

4. National Malaria Elimination Programme (NMEP), National Population Commission (NPopC), National Bureau of Statistics (NBS), and ICF International. Nigeria Malaria Indicator Survey 2015. Abuja, Nigeria, and Rockville, Maryland, USA: NMEP, NPopC, and ICF International; 2016 
5. Aregbeshola BS, Khan SM. Factors affecting the uptake of malaria prevention strategies among pregnant women in Nigeria: evidence from 2013 Nigeria demographic and health survey. Journal of Public Health: From Theory to Practice. 2018; https://doi.org/10.1007/s10389-017-0877-1

6. World Health Organization. WHO policy brief for the implementation of intermittent preventive treatment of malaria in pregnancy using sulfadoxine-pyrimethamine (IPTp-SP). Geneva: World Health Organization; 2016

7. Federal Ministry of Health. National Malaria Strategic Plan 2014-2020. Abuja, Nigeria: FMoH;2014. Retrieved from https://www.health.gov.ng/doc/NMEP-Strategic-Plan.pdf

8. Mlugu EM, Minzi O, Asghar M, Farnert A, Kamuhabwa AAR, Aklillu E. Effectiveness of SulfadoxinePyrimethamine for Intermittent Preventive Treatment of Malaria and Adverse Birth Outcomes in Pregnant Women. Pathogens. 2020; 9, 207; doi:10.3390/pathogens9030207

9. Esu E, Effa E, Udoh E, Oduwole O, Odey F, Chibuzor M, Oyo-Ita A, et al. Utilization of intermittent preventive treatment for malaria among pregnant women attending antenatal clinics in health facilities of Cross River State, Nigeria. Research and Reports in Tropical Medicine. 2013; 4:29-35, http://dx.doi.org/10.2147/RRTM.S47677

10. Thiam S, Kimotho V, Gatonga P. Why are IPTp coverage targets so elusive in sub- Saharan Africa? A systematic review of health system barriers. Malar J. 2013; 12:353, https://doi.org/10.1186/14752875-12-353

11. Awantang GN, Babalola SO, Koenker H, Fox KA, Toso M, Lewicky N. Malaria- related ideational factors and other correlates associated with intermittent preventive treatment among pregnant women in Madagascar. Malar J. 2018; 17:176, https://doi.org/10.1186/s12936-018-2308-3

12. Balami AD, Said SM, Zulkefli NAM, Bachok N, Audu B. Determinants of uptake of first dose of intermittent preventive treatment among pregnant women in a secondary health Centre in Maiduguri, Nigeria. BMC Pregnancy and Childbirth. 2020; 20:726, https://doi.org/10.1186/s12884-020-03388-8

13. Mushi V, Mbotwa CH, Zacharia A, Ambrose T, Moshi FV. Predictors for the uptake of optimal doses of sulfadoxine-pyrimethamine for intermittent preventive treatment of malaria during pregnancy in Tanzania: further analysis of the data of the 2015-2016 Tanzania demographic and health survey and malaria indicator survey. Malar J. 2021; 20:75, https://doi.org/10.1186/s12936-021-03616-2

14. Sangho O, Tounkara M, WhitingCollins LJ, Beebe M, Winch PJ, Doumbia S. Determinants of intermittent preventive treatment with sulfadoxine-pyrimethamine in pregnant women (IPTp-SP) in Mali, a household survey. Malar J. 2021; 20:231, https://doi.org/10.1186/s12936-021-03764-5

15. Muhammad FM, Nedjat S, Sajadi HS, Parsaeian M, Assan A, Majdzadeh R. Malaria intermittent preventive treatment in Nigeria: a qualitative study to explore barriers. BMC Infectious Diseases. 2021; 21:438, https://doi.org/10.1186/s12879-021-06135-2

16. Andrews KG, Lynch M, Eckert E, Gutman J. Missed opportunities to deliver intermittent preventive treatment for malaria to pregnant women 2003-2013: a systematic analysis of 58 household surveys in sub-Saharan Africa. Malar J. 2015; 14:521, doi: 10.1186/s12936-015-1033-4 
17. Diala CC, Pennas T, Marin C, Belay KA. Perceptions of intermittent preventive treatment of malaria in pregnancy (IPTp) and barriers to adherence in Nasarawa and Cross River States in Nigeria. Malar J. 2013; 12:342, doi: 10.1186/1475-2875-12-342

18. Ameh S, Owoaje E, Oyo-Ita A, Kabiru CW, Akpet OEO, Etokidem A, Enembe O, et al. Barriers to and determinants of the use of intermittent preventive treatment of malaria in pregnancy in Cross River State, Nigeria: a cross-sectional study. BMC Pregnancy and Childbirth. 2016; 16:99, doi: 10.1186/s12884-016-0883-2

19. Akpa CO, Akinyemi JO, Umeokonkwo CD, Bamgboye EA, Dahiru T, Adebowale AS, et al. Uptake of intermittent preventive treatment for malaria in pregnancy among women in selected communities of Ebonyi State, Nigeria. BMC Pregnancy and Childbirth. 2019; 19:457, https://doi.org/10.1186/s12884019-2629-4

20. Muhammad FM, Majdzadeh R, Nedjat S, Sajadi HS, Parsaeian M. Socioeconomic inequality in intermittent preventive treatment using Sulphadoxine pyrimethamine among pregnant women in Nigeria. BMC Public Health. 2020; 20:1860, https://doi.org/10.1186/s12889-020-09967-w

21. AmoakohColeman M, Arhinful DK, KlipsteinGrobusch K, Ansah EK, Koram KA. Coverage of intermittent preventive treatment of malaria in pregnancy (IPTp) infuences delivery outcomes among women with obstetric referrals at the district level in Ghana. Malar J. 2020; 19:222, https://doi.org/10.1186/s12936-020-03288-4

22. Buh A, Kota K, Bishwajit G, Yaya S. Prevalence and Associated Factors of Taking Intermittent Preventive Treatment in Pregnancy in Sierra Leone. Trop. Med. Infect. Dis. 2019; 4, 32, doi:10.3390/tropicalmed4010032

23. OwusuBoateng I, Anto F. Intermittent preventive treatment of malaria in pregnancy: a crosssectional survey to assess uptake of the new sulfadoxine-pyrimethamine five dose policy in Ghana. Malar J. 2017; 16:323, doi: 10.1186/s12936-017-1969-7

24. Adewole AO, Fawole O, Ajayi I, Yusuf B, Oladimeji A, Waziri E, et al. Determinants of intermittent preventive treatment of malaria among women attending antenatal clinics in primary health care centers in Ogbomoso, Oyo State, Nigeria. Pan African Medical Journal. 2019; 33:101, doi:10.11604/pamj.2019.33.101.14800

25. Onoka CA, Hanson $\mathrm{K}$, Onwujekwe OE. Low coverage of intermittent preventive treatment for malaria in pregnancy in Nigeria: demand-side influences. Malar J. 2012; 11:82, https://doi.org/10.1186/14752875-11-82

26. Amoran $\mathrm{OE}$, Ariba AA, lyaniwura $\mathrm{CA}$. Determinants of intermittent preventive treatment of malaria during pregnancy (IPTp) utilization in a rural town in Western Nigeria. Reproductive Health. 2012; 9:12, https://doi.org/10.1186/1742-4755-9-12

27. Iliyasu Z, Gajida AU, Galadanci HS, Abubakar IS, Baba AS, Jibo AM, et al. Adherence to intermittent preventive treatment for malaria in pregnancy in urban Kano, northern Nigeria. Pathogens and Global Health. 2012; 106[6]: 323-329, http://dx.doi.org/10.1179/2047773212Y.0000000037 
28. Olugbade OT, Ilesanmi OS, Gubio AB, Ajayi I, Nguku PM, Ajumobi O. Socio-demographic and regional disparities in utilization of intermittent preventive treatment for malaria in pregnancy - Nigeria demographic health survey 2013. ThePan African Medical Journal. 2019; 32[Supp 1]: 13, doi: 10.11604/pamj.supp.2019.32.1.13345

29. Abbey M, Bartholomew LK, Chinbuah MA, Gyapong M, Gyapong JO, van den Borne B. Development of a theory and evidence-based program to promote community treatment of fevers in children under five in a rural district in Southern Ghana: An intervention mapping approach. BMC Public Health. 2017; 17[120]: 1-11, doi: 10.1186/s12889-016-3957-1

30. Nyaaba GN, Olaleye AO, Obiyan MO, Walker O, Anumba DOC. A socio-ecological approach to understanding the factors influencing the uptake of intermittent preventive treatment of malaria in pregnancy (IPTp) in South-Western Nigeria. PLoS ONE. 2021; 16[3]: e0248412, https://doi.org/10.1371/journal.pone.0248412

31. Andersen RM. Revisiting the behavioural model and access to medical care: does it matter? J Health Soc Behav. 1995; 36[1]: 1-10

32. Aday LA, Andersen R. Health care utilization and bevavior, models of. InArmitage P. Colton. Eds. Encyclopaedia of Biostatistics. Chichester: John Wiley \& Sons; 1998

33. Andersen RM. National health surveys and the behavior model of health services uses. Medical Care. 2008; 46[7]: 647-653

34. Tolera H, Gebre-Egziabher T, Kloos H. Using Andersen's behavioral model of health care utilization in a decentralized program to examine the use of antenatal care in rural western Ethiopia. PLoS ONE. 2020; 15[1]: e0228282, https://doi.org/10.1371/journal.pone.0228282

35. Solanke BL. Do the determinants of institutional delivery among childbearing women differ by health insurance enrolment? Findings from a population-based study in Nigeria. Int J Health Plann Mgmt. 2021; 36[3]: 668-688, https://doi.org/10.1002/hpm.3112

36. Azfredrick EC. Using Anderson's model of health service utilization to examine use of services by adolescent girls in south-eastern Nigeria. International Journal of Adolescence and Youth. 2016; 21[4]: 523-529, https://doi.org/10.1080/02673843.2015.1124790

37. Seidu A-A. Using Anderson's Model of Health Service Utilization to Assess the Use of HIV Testing Services by Sexually Active Men in Ghana. Front. Public Health. 2020; 8[512]: 1-10, doi: 10.3389/fpubh.2020.00512

38. Mbalinda SN, Kaye DK, Nyashanu M, Kiwanuka N. Using Andersen's Behavioral Model of Health Care Utilization to Assess Contraceptive Use among Sexually Active Perinatally HIV-Infected Adolescents in Uganda. International Journal of Reproductive Medicine. 2020; 8016483, https://doi.org/10.1155/2020/8016483

39. Travers JL, Hirschman KB, Naylor MD. Adapting Andersen's expanded behavioral model of health services use to include older adults receiving long-term services and supports. BMC Geriatrics. 2020; 20[58]: 1-16, https://doi.org/10.1186/s12877-019-1405-7 
40. National Population Commission, ICF. Nigeria Demographic and Health Survey 2018. Abuja, Nigeria and Rockville, Maryland, USA: NPC \&ICF;2019

41. Adedokun ST, Uthman OA. Women who have not utilized health Service for Delivery in Nigeria: who are they and where do they live? BMC Pregnancy Childbirth. 2019:19(93), https://doi.org/10.1186/s12884-019-2242-6

42. Solanke BL, Rahman AS, Ogunjuyigbe PO. To what extent do community characteristics drive health facility delivery? Findings among Women who had recent live births in Nigeria. Health Soc Care Community. 2021; 29[4]: 992-1000, https://doi.org/10.1111/hsc.13133

43. Solanke BL, Amoo EO, Idowu AE. Improving postnatal check-ups for mothers in West Africa: a multilevel analysis. Women \& Health. 2018; 58[2]: 221-245, https://doi.org/10.1080/03630242.2017.1292343

44. Solanke BL. Individual and Community factors associated with indications of caesarean delivery in Southern Nigeria: Pooled analyses of 2003-2013 Nigeria Demographic and Health Surveys. Health Care for Women International. 2018; 39[6]: 697-716, https://doi.org/10.1080/07399332.2018.1443107

45. Solanke BL. Household Wealth, Decision-Making and High Parity Pregnancies in Nigeria. Women's Reproductive Health. 2021; 8[1]: 44-59, https://doi.org/10.1080/23293691.2020.1861411

46. Daoud JI. Multicollinearity and regression analysis. IOP Conf. Series: Journal of Physics: Conf. 2017; 949:012009, doi:10.1088/1742-6596/949/1/012009

47. Snijders TAB. Fixed and Random Effects. In Everitt, B. S., \& Howell, D. C. (eds), Encyclopedia of Statistics in Behavioral Science. Chichester: Wiley. 2005; 2: 664-665, https://doi.org/10.1002/0470013192.bsa234

48. StatCorp. Stata: Release 14. Statistical Software. College Station, TX: StataCorp LP;2015 